\title{
Lightweight bonded acrylic facing at the Vitra VSL Factory
}

\author{
Matthias Michel ${ }^{a, b, *}$ and Holger Techen ${ }^{b, c}$ \\ ${ }^{a}$ Delft University of Technology, Faculty of Architecture and The Build Environment, \\ Architectural Engineering \& Technology, Julianalaan, The Netherlands \\ ${ }^{\mathrm{b}}$ Imagine structure, Diesterwegstr., Frankfurt am Main, Germany \\ ${ }^{c}$ Frankfurt am Main University of Applied Sciences, Faculty of Architecture, \\ Nibelungenplatz, Frankfurt am Main, Germany
}

Received first submission: 2009

Received upgraded version: 16 August 2013

Accepted: 23 October 2013

\begin{abstract}
Acrylic glass is omnipresent in the industrialised world; but as a building material most architects, facade planners and engineers are still unfamiliar with this material. In most cases it is applied as a substitute for glass which leads to inappropriate joints and fixtures. During the years of the path toward the digital era, the authors were in the fortunate position to be involved in several unconventional glass and acrylic glass projects. On the basis of their most recent project, the facade of the Vitra VSL Factory by SANAA Architekten, they describe the development of a facade for which they chose acrylic glass not as a substitute for glass but rather as a conscious material choice. Since the entire facade is it was possible to apply the manufacturing technology of deep-drawing, allowing for very thin wall thicknesses.
\end{abstract}

Keywords: Facade design, structural analysis, building envelopes, cladding, acrylics

\section{Acrylic glass is more than a mere substitute for glass}

In the building environment, acrylic glass plays a subordinate role, and is mostly integrated into products that - as plug-and-play solutions - do not require in-depth planning and material discussions. Building envelopes consisting of acrylic glass are rare. And for these occasional facade projects acrylic glass is used as a 'substitute' for glass; the goal is to achieve the appearance of glass but using glass itself seems impractical; processing is too expensive and/or elaborate. These projects usually feature complex surface curvatures with no or very few equal surface sections. Thus, acrylic glass is used as a substitute for glass, and the deviating qualities and characteristics are put up with. The joining methods for these solutions are borrowed from building with glass; using clamps and point fixtures, for example. The error of thinking you are dealing with a glass made off plastic harbours the risk of constructing in a manner that does not comply with the material used.

The authors' opinion is that a thorough knowledge of the material in question is critical. It offers a broader range of architectural expression if used as an independent material and is thus integrated into the design process. The façade of the Vitra VSL Factory is an example; acrylic glass with an opaque background is used to create a curtain, literally; and the image of the curtain is reflected by the slender shape and the method of construction and fixtures.

\footnotetext{
*Corresponding author: Matthias Michel, E-mail: michel@imagine-structure.eu.
} 
The sensitivity of the material requires thorough knowledge of the material properties - as they are described in the following - during the early concept phase. Façade panels should be mounted in a way that avoids stress concentration. In order to achieve this with the Vitra façade, the panels were mounted with a glue joint on the rear side - for the first time without providing for mechanical protection. Rather, the authors developed a redundancy system with which defects resulting from potential failure of the primary support structure can be detected from the outside. The fragile façade material and the technique of glue joining combine into a harmonised technology which will be described in the following.

\section{Working with acrylic glass}

The correct material name for acrylic glass is polymethylmethacrylate, abbr. PMMA. It belongs to the group of thermoplastic materials and consists of a dense mesh of arbitrarily braided long molecular chains. The individual molecule has the shape of a loose ball of yarn. Each ball is penetrated by the neighbouring ball. However, the rigidity of this inner structure loosens with increasing temperatures (Ehrenstein, 1999).

Besides its transmissive properties and easy processability, an important advantage of the material is the possibility to reshape it under temperature - even into two-dimensionally curved geometries. Its problematic reputation in the building industry results from material characteristics that are atypical for many other building materials. A brief description of these characteristics is provided in the following.

- Relaxation: Just like most thermoplastics acrylic glass tends to creep. Under long-term stress component deformation increases according to the viscoelastic behaviour of PMMA.

- Structure: Despite good short-term strength and impact resistance, prolonged and regularly reoccurring stress must be kept below the level at which crazes, i.e. micro defects in the form of detanglement of the molecules occur at increased rates. When crazes are present, the inhomogeneity of the structure can cause cracks with according notch stress. A large number of crazes also increases the tendency to creep (Ehrenstein, 1999).

- Joining: Load application and joining require special constructive consideration and high quality workmanship. Hereby, edge smoothness of boreholes and cut edges is very important for the load-bearing capacity.

- Chemical resistance: Acrylic glass is sensitive to alcohols and other solvents. It tends to stress fracture corrosion.

- Temperature: One remarkable material property is the large expansion coefficient. At $70^{*} 10^{-6}$ $\mathrm{K}^{-1}$ it is six times higher than that of steel and approximately ten times higher than that of glass. This results in special requirements regarding zero-stress installation of components. In case of load-bearing building parts the temperature load cases play an important role in the calculation. And the mechanical properties are temperature dependent; a factor that needs to be considered during trial conceptualisation and the layout of statically undetermined systems.

- UV light resistance: Contrary to common belief acrylic glass is completely UV proof. Often, other non UV proof translucent plastics are mistaken for acrylic glass.

- Reaction to fire: Similar to most other translucent plastics acrylic glass is normally inflammable; however without flaming droplets and burning almost entirely pollutant-free.

- Production: Since manufacturers add different auxiliaries such as surfactants to the base material, material properties vary. This means that it is necessary to retrieve a binding product and project 
specific material data sheet at the beginning of the project. Tests and trials have to be conducted repeatedly.

- PMMA is not included in the Buildings Rules Lists. There is no building-related standardisation. A dimensioning concept can be derived from (Baü̈berwachungsverein, 2010).

The list of the most important properties shows that the commonalities with glass are limited to transparency and surface appearance. In practice, the properties atypical for building materials make it difficult for the planner or architect to assess feasibility or plausibility of a façade concept that uses acrylic glass.

How can the feasibility of an acrylic glass project be assessed without pertinent experience? The authors' findings gained from previous projects condense into a model-like comparison with a well known building material. Considering constructive and process-related aspects in addition to the mechanical properties, birch or beech veneer plywood closely resembles acrylic glass. Roughly described, acrylic glass and plywood have similar design strength, even though the specific weight of acrylic glass is twice that of plywood and its stiffness is a third less. Despite these deviations the comparison of plywood and acrylic glass has proven to be applicable for all of our projects, and it is useful to validate a concept: if it is conceivable in plywood it can also work with acrylic glass (Michel, 2010) (Bauüberwachungsverein, 2010).

\section{Facade of the Vitra VSL Factory, Weil am Rhein}

For the façade of the distributing warehouse project for Vitra AG in Weil am Rhein by Japanese architects SANAA, the authors developed a structural design with which they participated in a tender: a round building, approximately $150 \mathrm{~m}$ in diameter, $12 \mathrm{~m}$ high, is to be enveloped by a light shell with an immaterial appearance in the form of a white undulating curtain. The exterior walls of the industrial building feature only few gates, entrances and windows; the light curtain and the rounded shape soften the harshness of the building. Technical details were to be kept absolutely invisible. The Tokyo designers and local partners chose a thermoplastic material for the façade plane.

The architects' execution concept envisions a small number of differently shaped vertical panels which, arranged in an intelligent sequence create a pseudo-random wave formation. The distance between waves lies between 15 and $40 \mathrm{~cm}$, and the wave depth is approximately $20 \mathrm{~cm}$.

There were no fire protection requirements for the facade since it forms a separate shell in front of a mostly enclosed steel concrete wall. Thus, off the shelf co-extruded acrylic glass was the material of choice; one transparent layer and one white imbued layer are melted together, creating a white surface with a transparent coating. The visual effect of the material is appealing; mainly due to the glossiness of the transparent coat. In order to underline the desired abstract effect and to ensure material appropriate mounting, the panels of the shell are glued onto the substructure without visible fixtures, and the shell is positioned in front of the near windowless reinforced concrete exterior wall.

\subsection{Acrylic glass - technology}

According to German Building Code a façade construction made of acrylic glass requires approval on a case-by-case basis, in the course of which its stability and durability are tested, e.g. by trials, and an operating manual is compiled for the user. 


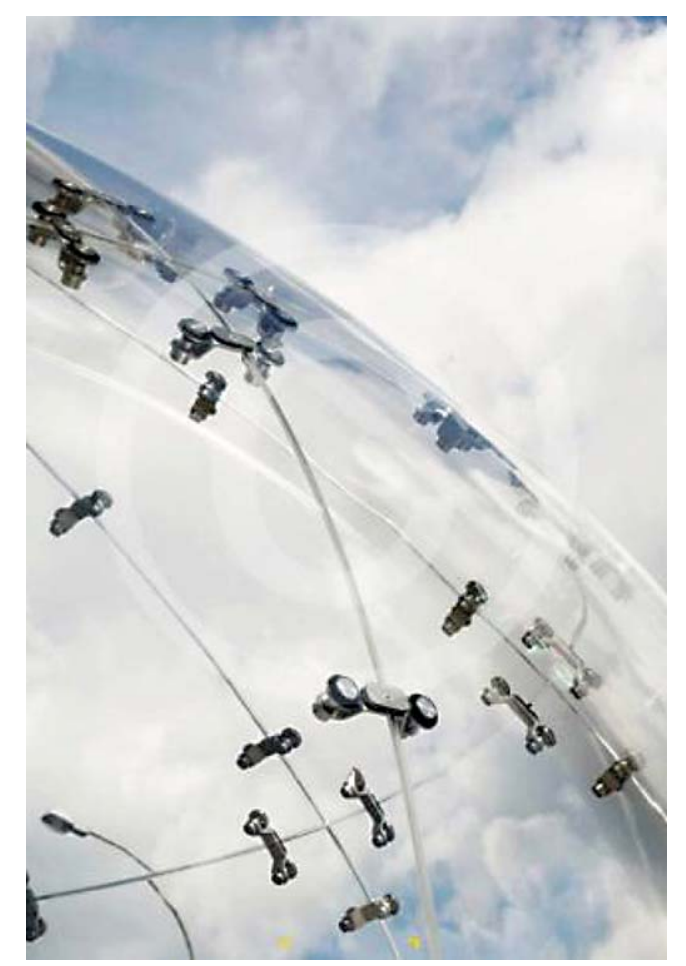

Fig. 1. Acrylic glass as a substitute for glass: joints with point fixtures on the acrylic glass shell of the BMW hourglass (Photo: Photodesigner).

In their function as engineers, the authors were able to accompany the façade project through the approval process up until its execution and completion by the general contractor, and develop it further in a team that already worked on projects such as Kunsthaus Graz and the Nordkettenbahn Innsbruck.

The façade panels have no horizontal joints but are manufactured as $12 \mathrm{~m}$ long components that are suspended. The material thickness is very low (few millimetres) in relationship to the panel dimensions. Deformation takes place in a custom built oven by deep drawing at approximately $160^{\circ} \mathrm{C}$. The $6.5 \mathrm{~mm}$ thick semi-finished part is mounted into a clamp frame on the edge of the CNC-milled and hand polished positive mould and heated. Applied vacuum sucks the hot acrylic glass into the mould (Fig. 5). The deep drawing process locally reduces the initial thickness to some extent. This entire process takes place inside the oven. Deformation and cooling off are computer controlled, and are monitored from the outside. Subsequently each panel is tempered to relax stress or tension in the material created by the cooling process. A 5 -achsis mill is used to trim around all sides to create the open upper and lower edges of the façade; an important feature to achieve the abstract appearance of the façade (Fig. 6).

The above mentioned high thermal expansion also has an effect on the manufacturing process. It is easily conceivable how much a life of its own the $12 \mathrm{~m}$ long and few millimetres thick blank takes on during production when it is heated by $140^{\circ} \mathrm{K}$, deformed, cooled off and finally relaxed at $80^{\circ} \mathrm{C}$. Therefore an important characteristic of this building project - as of most others that include 

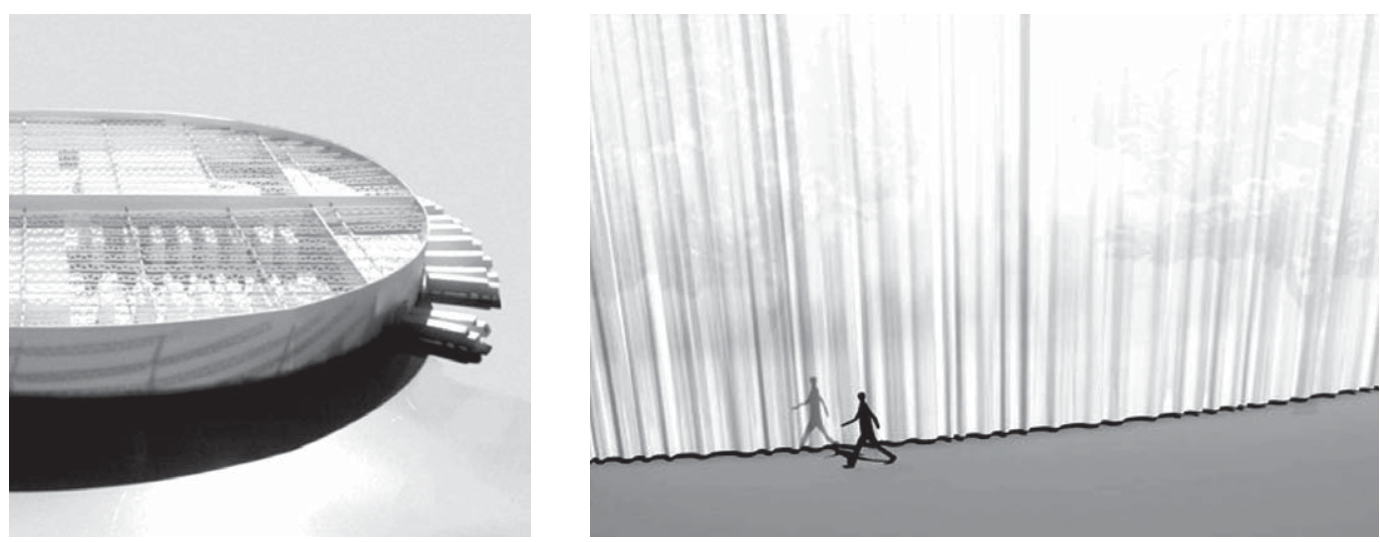

Figs. 2, 3. Study of the structure and façade visualisation (Images: SANAA, nkbak).

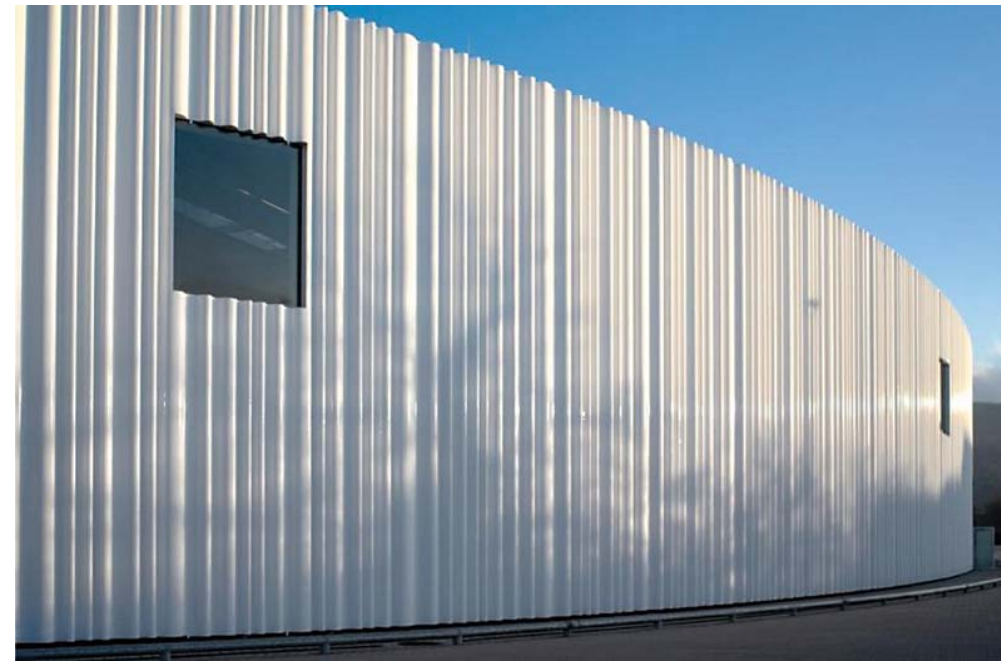

Fig. 4. Completed façade section (Image: Michel).

free-formed elements - is that it would not be feasible without computer-assisted production but that material specific knowledge and experience determine ultimate failure or success.

On the building, the panel is subjected to wind loads of approximately $1 \mathrm{kN} / \mathrm{m}^{2}$ and temperature fluctuations of $\pm 40^{\circ} \mathrm{K}$. For the top mounted $12 \mathrm{~m}$ long panel this results in contraction or elongation of $35 \mathrm{~mm}$ at the lower end.

According to the early concept which was then further developed and fine-tuned with the team of façade execution planning the panel's rear side is glued onto an aluminium substructure which in turn is joined to the insulated reinforced concrete wall with gliding fixtures. These consist of horizontal latch profiles that are hooked into wall-mounted hooks. On the profiles are so-called glue fixtures onto which the acrylic glass panels are mounted at the indentations between the wave crests. Between the latches with the glue fixtures the panel hangs free because the undulating form provides sufficient stiffness. Only the edges, which are partially flattened, are designed to be supported with a stiffening 

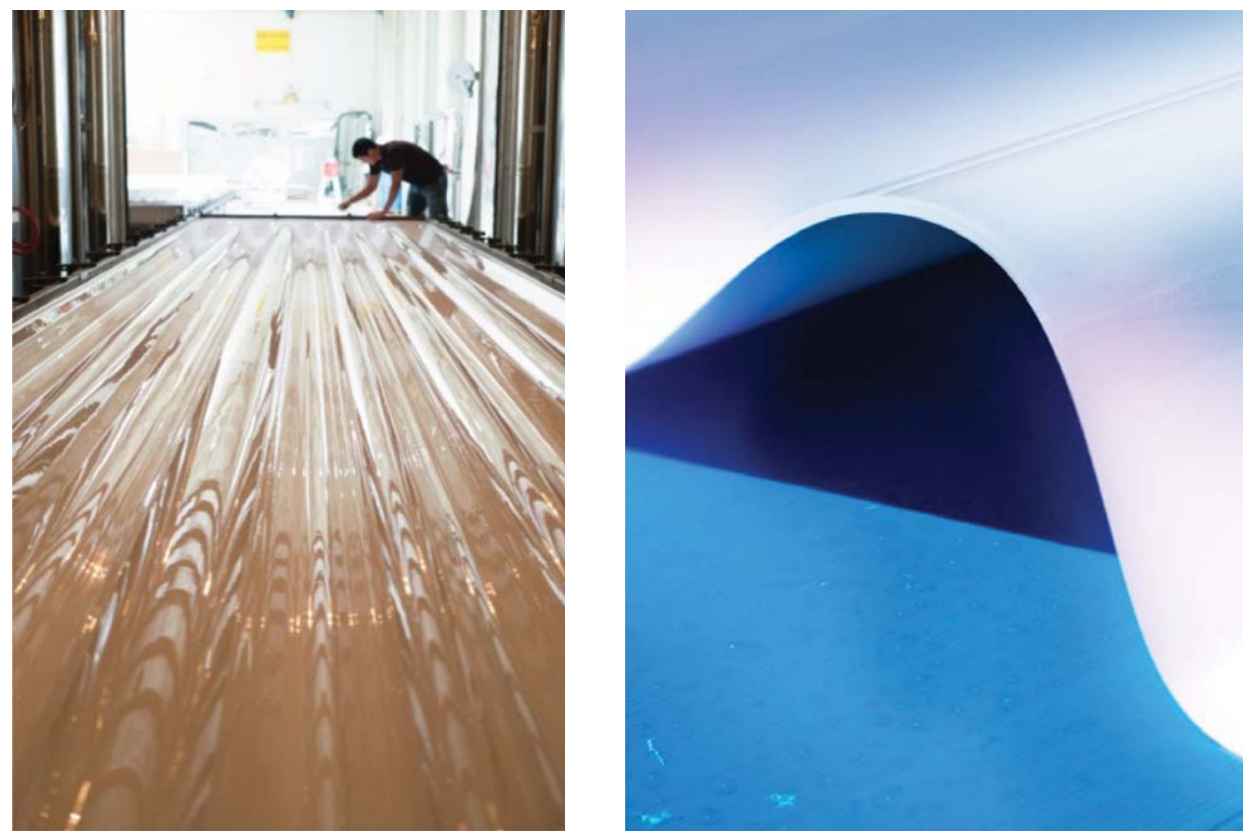

Figs. 5, 6. Deep drawn panel in the oven - Wave section made of co-extruded acrylic glass (Images: Michel).

profile to avoid deformation. Glue fixtures are hooked onto these as well; cutting the panels' edge span widths in half (Figs. 7, 8).

The panel's own weight is dissipated at the top end. Conforming to the visual appearance of a curtain it is suspended from the parapet level, and horizontally fastened in regular intervals to withstand wind loads. This method of vertical mounting is an important feature that allows for the low thickness of the material. The relaxation behaviour of the material and warm temperatures would eventually cause a bottom-mounted panel to take on a progressively warped shape. Our first concept envisioned a lip along the upper edge of the panel, and the panel being suspended from this lip. Design aspects, however, caused us to vote for a hard cut edge, eliminating the possibility of simple mechanical mounting. Thus, the chosen solution involves glued fixtures on the rear side, also used to dissipate the panels' own weight, and foregoes mechanical mounting.

\subsection{Gluing method}

The conception and dimensioning of the glue fixtures is determined by the chosen gluing method. The adhesive must allow for large thicknesses to accommodate the different radii of the glue fixtures and the panel's curved shape. And it must allow for the different temperature expansion of aluminium and acrylic glass. It must be UV and heat resistant, and must be sufficiently strong under push and pull loads.

Double sided adhesive tape was neglected because of its low thickness and the resulting large number of different curvatures for which appropriate glue fixtures would have had to be produced. The best suited adhesive material found was polyurethane glue. However, in-depth research highlighted that its UV resistance under acrylic glass cannot be completely guaranteed at this time because 

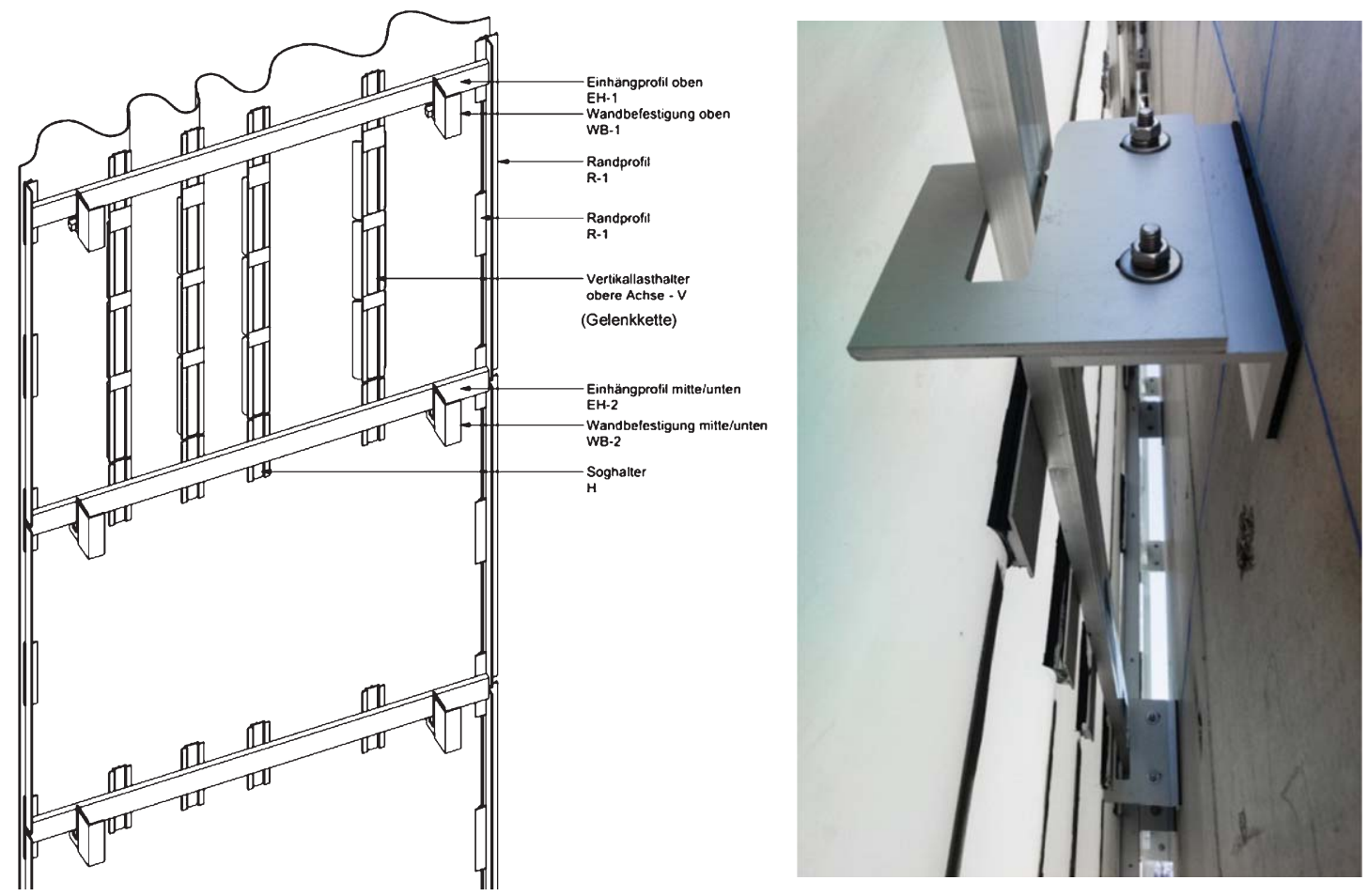

Figs. 7, 8. Illustration of panel substructure - Panel prototype during trial assembly without insulation (Images: imagine, Michel).

building scientific research is focussed on gluing glass, not acrylic glass. Since the UV permeable spectral ranges of glass and acrylic glass differ, no secured inference on the durability can be drawn form these studies. The planning timeframe for this particular project did not permit project based research.

Therefore, structural-glazing SG silicone is used for all glue fixtures of this project. It fulfils most of the mentioned requirements, but its suitability for long-term push loads as they occur in this application is limited. On the other hand, the existence of a technical approval guideline for SG silicones (ETAG002) facilitates further steps as it describes testing procedures for the certification of SG silicones and the according methods of dimensioning. Even though ETGA002 is limited to SG façades, i.e. façades with linear glued glass panes, it does provide tests which can be drawn upon for an approval for this particular project as is required for the described project (Hagl, 2007).

The testing program is set up in two phases. During the first phase tests are conducted with small samples under UV influence, and in cold and hot storage as they are defined according to ETAG 002. These tests are designed to show the properties of the silicone-PMMA glue joint referring to adhesion and cohesion. In our case, there were no significant limitations in comparison to the target values for glued joints of aluminium and glass. Cohesion was sufficiently researched during the ETA certification process for the silicone material; it, too, offers small risk of surprise, which means that compliance with the values of the ETAG is to be expected for these kinds of tests. 
The second testing phase involves pull tests on pull holders with the original geometry (length $10 \mathrm{~cm}$ to $30 \mathrm{~cm}$ ) (Fig. 9). For dimensioning glued joints, ETAG provides for a partial safety factor of 6 , with which the test results are attenuated (Hagl, 2007). With a $5 \%$ fractile of the breaking force of more than $10 \mathrm{kN}$ for the longest sample the gluing method proves suitable to absorb wind loads. Inconsistent silicone filling become clearly visible when breaking the glued joint. Thus, the tests are also useful in terms of quality assurance to generate a processing guideline and a QM concept, as was done in this case with the executing parties under accompaniment of the authorised expert.

Since closely defined tests do not lend themselves to research the resistivity of the thin and planar acrylic glass in a practical manner and not all special circumstances of the glue joints can be represented by testing, we have created thorough finite element models of each panel type and the most important special geometric situations in ANSYS. These finite element models exactly depict panel, glue joint and sub-structure of a panel section. To determine the material parameters of the hyperelastic material law, the setup of the pull tests was modelled and recalculated. Upon concordance of test and calculation the design resistances were derived from the generated tension. Since ETAG 002 is based on the simplified approach of even stress distribution it can be expected that, in certain areas, the FE calculated stresses lie above the design resistance values of the guideline, as was the case here (Hagl, 2007) (Figs. 10-12).

Whereas testing provided only good results in terms of adhesion, the research related to stress crack corrosion on acrylic glass narrowed the range of silicone candidates. With plastics, stress cracks occur under mechanical stress if the plastic material is simultaneously subjected to specific solvents. As a general rule, solvents and plasticizer-containing products that are to be in contact with acrylic glass must be tested for compatibility. With silicone, volatile components whose concentration is only critical during processing can corrode acrylic glass if pull stress is present. Hereby, at the time of processing, it is not the tension from external impact that is important but rather embedded tension that results from thermal deformation without subsequent tempering.

The design of the glue joints on the sub-structure strictly follows the type of stress incurred (Figs. 7, 14). The glue mounts mounted in a row onto the latch profiles accommodate horizontal wind loads only. At the upper end there are additional load-bearing mounts that carry the own-weight of the panel. They are suspended from the uppermost latch profile which is rigidly coupled to the reinforced concrete wall on consoles. As mentioned before silicone is not an optimal adhesive for permanent push loads because this type of joint tends to creep. Therefore, the allowable stress for such a glue joint is low and requires large glue areas. (ETAG limits this type of stress to accordingly qualified products for class IV. Prerequisite is successful completion of a 90 -day test at $55^{\circ} \mathrm{C}$ and $90 \%$ humidity. The product of the partial safety factors versus permanent push loads results in a factor of 60 ). The vertical load mounts are therefore large. They are made of angled sheet metal; the curvature matches that of the individual wave shapes. Due to their length, the vertical load mounts are designed as a three-membered sprocket chain, so that they do not add rigidity under wind loads and absorb push loads only.

\subsection{Redundant fixtures}

Despite 90 days of push tests as part of the approval phase, the option of a mechanical safety device was still on the table because no results of long-term material specific research are yet available. However, the goal is to avoid visible mechanical protection at the upper edge of the panel. 

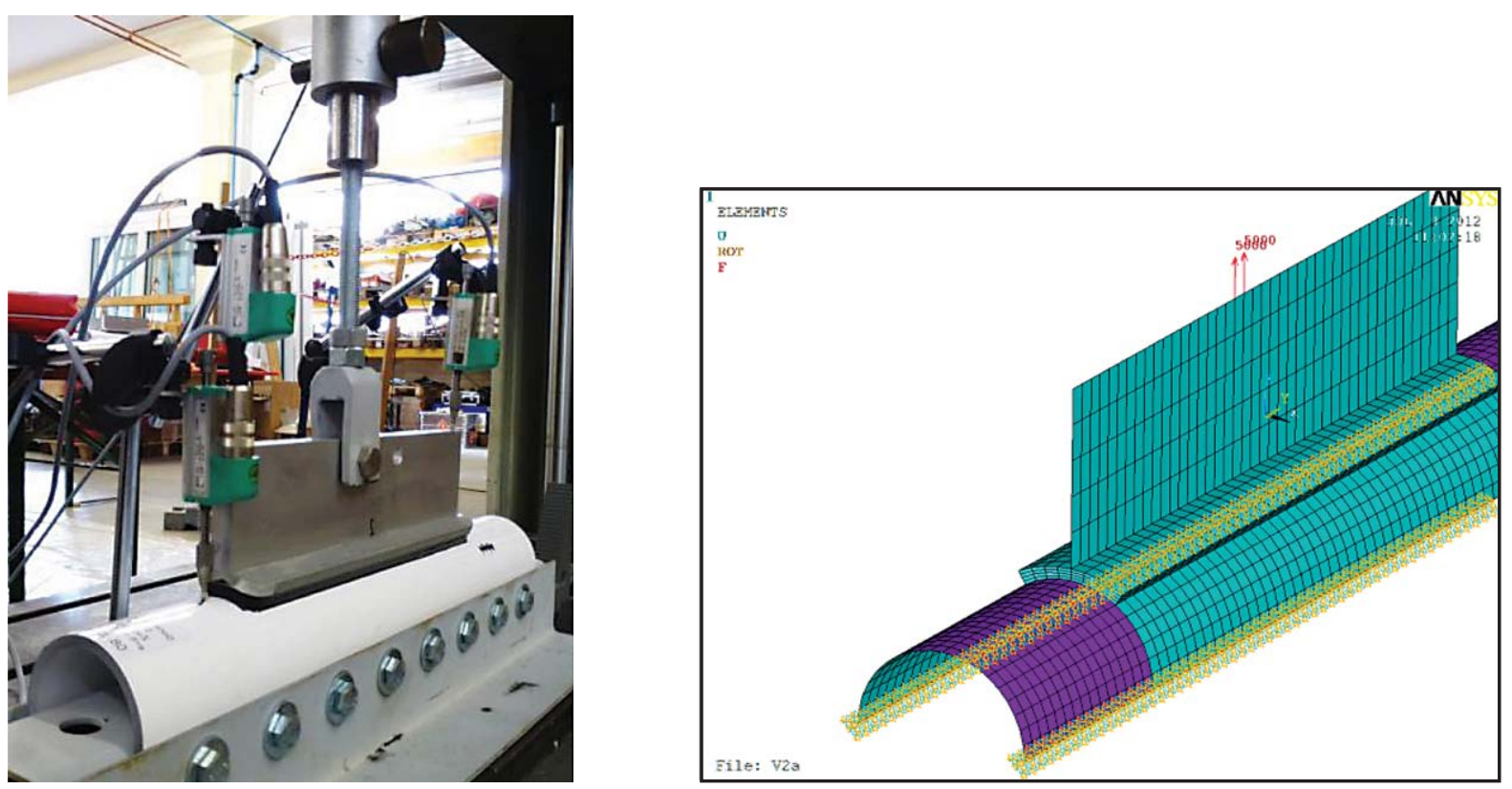

Figs. 9, 10. Test: gluing the pull holder and according FE model (Images: Michel).

.90322
1.51751
$i .50839$
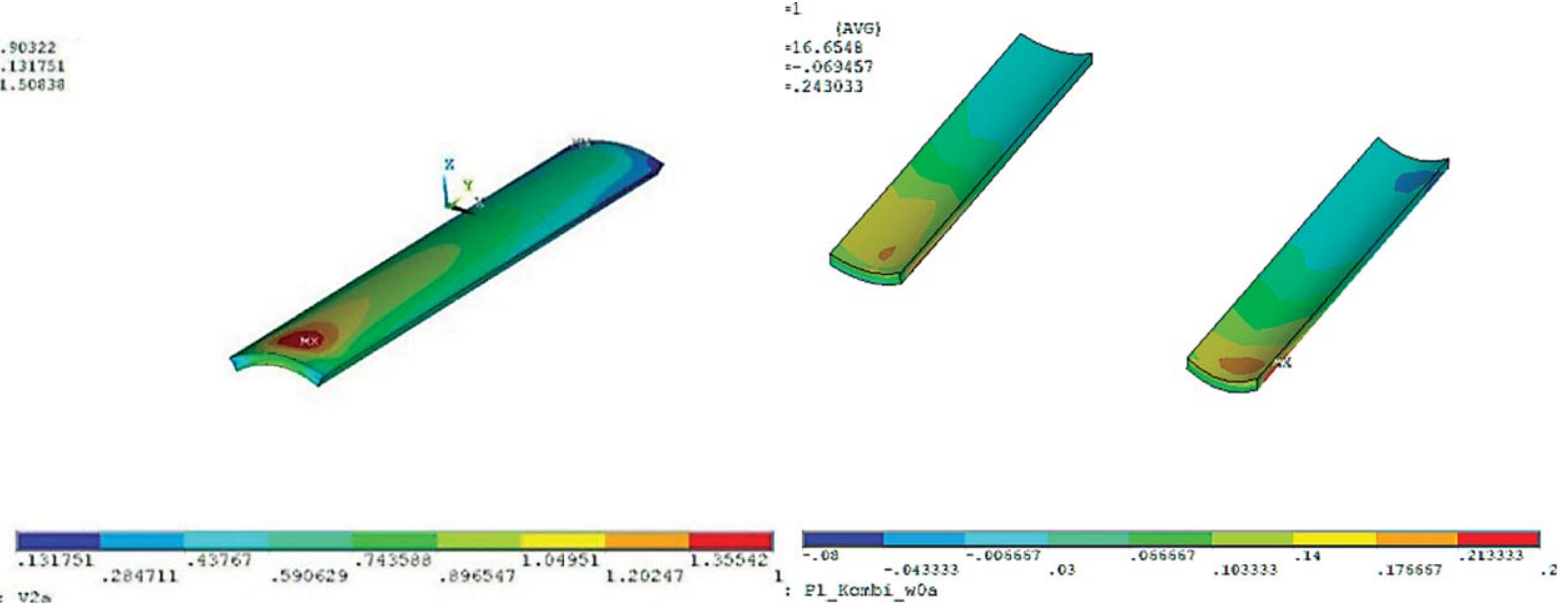

Figs. 11, 12. Recalculation of the silicone tension for the pull test from fig. 9 (eccentric load) - tension distribution glue joint in the panel model (Images: imagine).

Therefore the substructure is designed such that a redundancy is achieved in case of failure of the push glue joints. In this unlikely case the glue joints would detach the load mounts, and the panel together with the remaining substructure and the hereon mounted glue mounts would slide downward. This means that the panel with the remaining latch profiles falls a few centimetres into the wall-mounted hooks whose original purpose is to dissipate wind loads. In this case all glue joints 


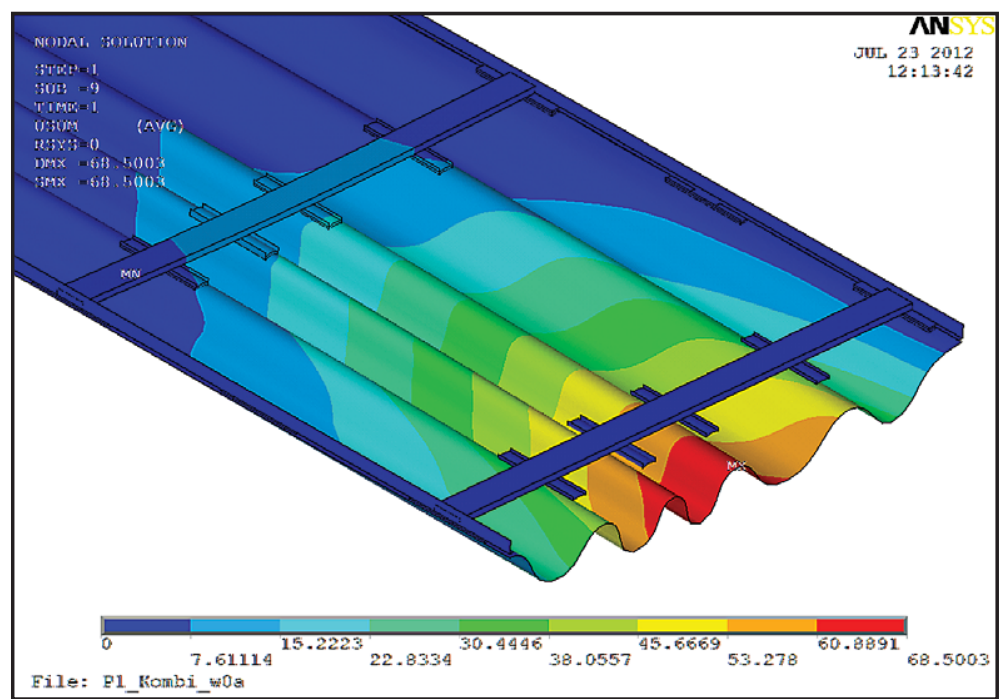

Fig. 13. FE simulation mount failure (Image: imagine).

Paneel in normalen Zustand

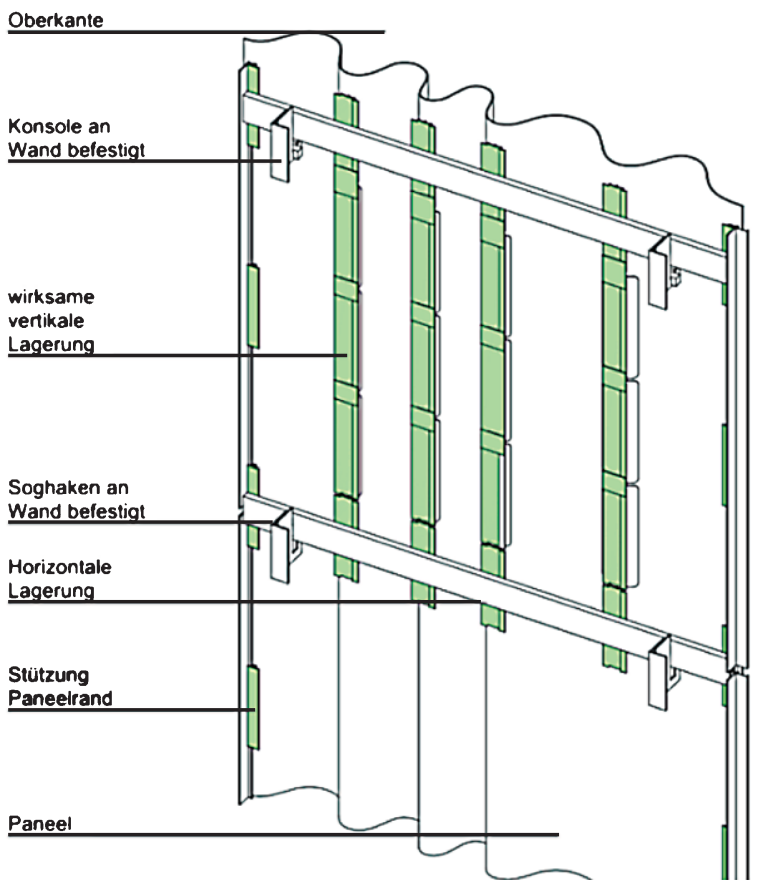

Vertikale Lagerung ausgefallen

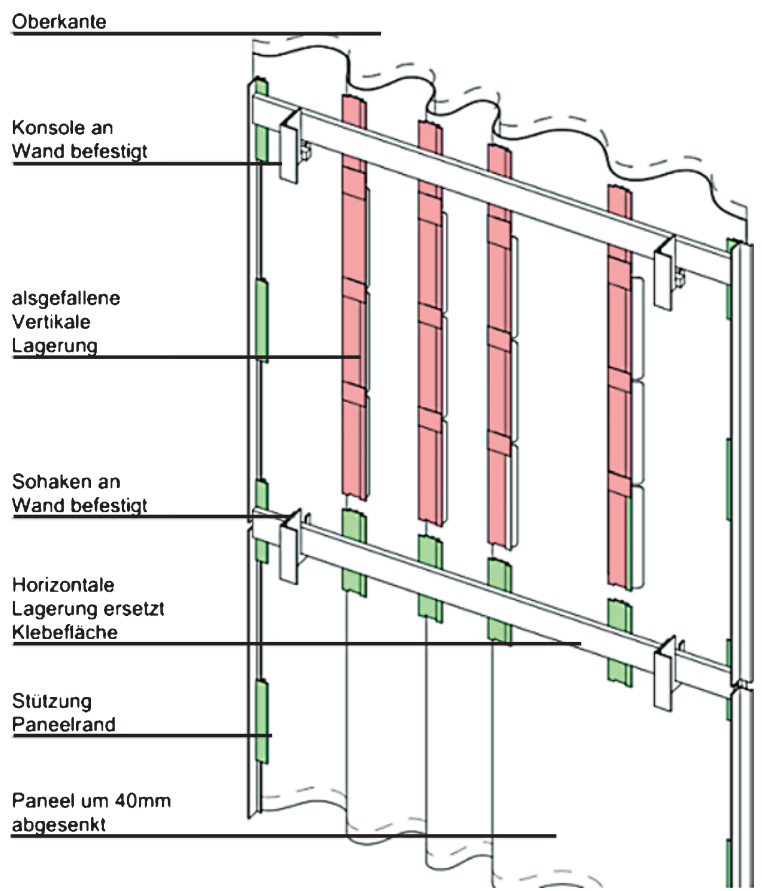

Figs. 14, 15. Functionality of the redundant push glue joints (green = intact; red =failure) (Images: imagine). 

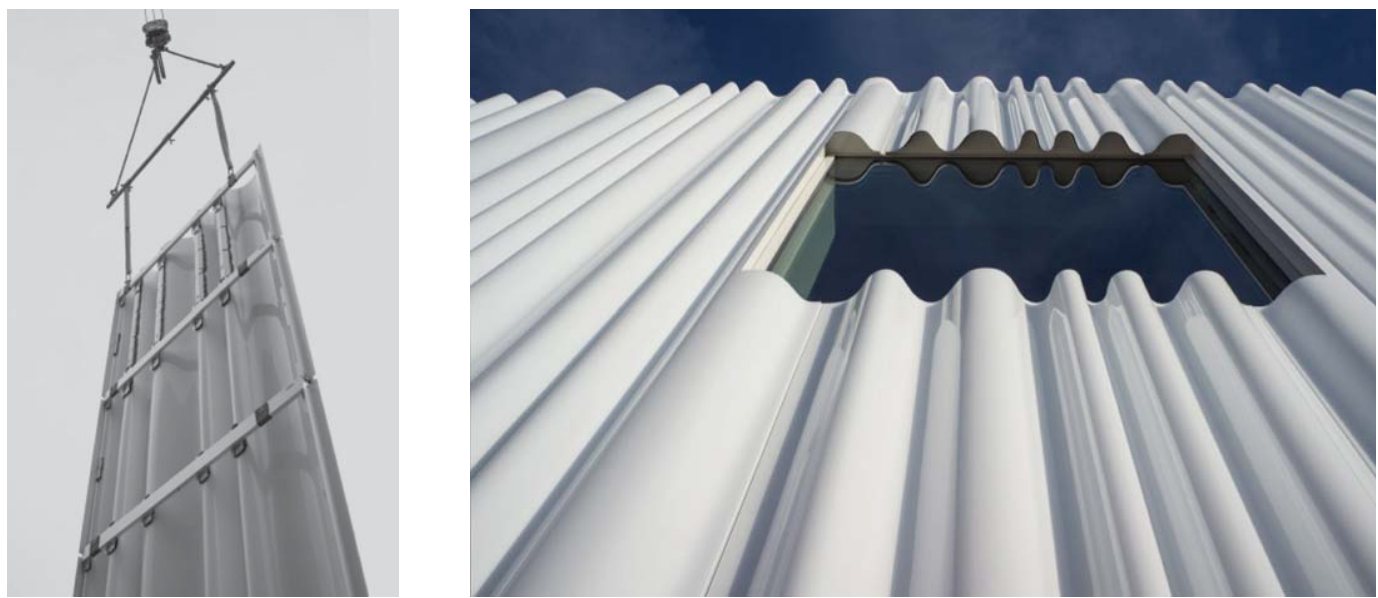

Figs. 16, 17. Rear side of a panel during assembly - completed façade section (Images: Michel).

of the pull mounts temporarily participate in carrying the weight of the panel (Figs. 14, 15). The upper end of the panel is also no longer protected against wind suction, and is held as a cantilever arm from the second row of mounts. Specific detailing makes it possible that in case of failure all edge mounts remain effective so that only the waves in the middle section of the panel have to serve as cantilever arms (Fig. 13). Panel failure can easily be detected from the outside because it hangs a few centimetres lower than the adjacent panels. Thus, timely identification and repair are possible.

Assembly is very easy; a support frame is used to erect a panel, then, after removing the support frame the panel is hooked into the mounts on the building shell (Fig. 16). In April 2013, the project with its 280 panels and just under $6000 \mathrm{~m}^{2}$ was completed after one and a half years of planning and execution.

\section{Conclusion}

The project report shows that the gluing method allows using large yet filigree plastics components on façades that could not be realised with mechanical fixtures. Gluing is particularly predestined for plastics materials that feature low firmness or tend to relaxation deformation under long-term loads.

However, the report also allows conclusions about the scope of the engineering constructive expenditure necessary to reach the goal of constructing a panel that is simply glued to a wall. It was helpful that already established standards, even though applied in other areas, of gluing with structural glazing silicone could be applied to acrylic glass, even if with some restrictions. More research needs to be done; in particular related to UV stability of polyurethane glue joints with acrylic glass because the permeability of glass and PMMA differ. The broader the knowledge in this field, the more we can expect a willingness to create plastic façades without mechanical fixtures on buildings of large vertical dimensions if other technical issues do not limit the size to that of low buildings. The only other remaining limiting factor will then be possible demands with regards to flammability of the material.

In the documented project, acrylic glass is not reduced to a substitute for glass but is considered an independent building material with unique characteristics; particularly as they result from joining transparent and white-opaque materials. 
Project imprint:

- Client Vitra AG, Weil am Rhein

- Architects SANAA, Tokyo and nkbak, Frankfurt

- General contractor Stabag AG, Direktion AO Metallica, M. Pagitz

- Acrylic glass panel production ktec $\mathrm{GmbH}$, Radstadt

- Building authority Landesstelle f. Bautechnik, Tübingen/Stuttgart

- Authorised expert Dipl.-Ing. Heinz Pfefferkorn

- façade execution planning gbd ZT, Dornbirn

- Testing laboratory gbd Lab, Dornbirn

- Inspection engineer Bernhard Strasser, Bad Säckingen

- Structural and façade engineering imagine Structure GmbH, Frankfurt

\section{References}

Bauüberwachungsverein. (2010). BÜV Empfehlung: Tragende Kunststoffbauteile im Bauwesen [TKB], Berlin.

Ehrenstein, G. (1999). Polymer-Werkstoffe: Struktur - Eigenschaften - Anwendung. (pp. 99-102). Munich: Hanser Verlag.

Hagl, A. (2006). Die Innovation - Kleben. Stahlbau, 75, 508-520

Hagl, A. (2007). Bemessung von strukturellen Silikon-Klebungen. Stahlbau, 76, 569-581

Knippers, J., Cremers, J., Gabler, M., \& Lienhard, J. (2011). Construction Manual for Polymers + Membranes, Munich: Birkhäuser Verlag.

Michel, M. (2010). Acrylic Facades, Three Case Studies. In U. Knaack, \& T. Klein (Eds.), The Future Envelope, 3, (pp. 1 -12). Amsterdam: IOS Press. 